\title{
The predictive value of creatinine clearance for mortality in patients undergoing revascularization
}

\author{
Eilon Ram ${ }^{1,2^{*}}$ (D), Pazit Beckerman ${ }^{2,3}$, Amit Segev ${ }^{2,4}$, Nir Shlomo ${ }^{2,4}$, Abigail Atlas-Lazar ${ }^{5}$, Leonid Sternik ${ }^{1,2}$ and \\ Ehud Raanani ${ }^{1,2}$
}

\begin{abstract}
Background: Renal function plays a significant role in the prognosis and management of patients with multi-vessel coronary artery disease (CAD) referred for revascularization. Current data lack precise risk stratification using estimated glomerular filtration rate (eGFR) and creatinine clearance.

Methods: This prospective study includes a three-year follow-up of 1112 consecutive patients with multi-vessel CAD enrolled in the 22 hospitals in Israel that perform coronary angiography.

Results: The Mayo formula yielded the highest mean eGFR $\left(90 \pm 26 \mathrm{~mL} / \mathrm{min}\right.$ per $\left.1.73 \mathrm{~m}^{2}\right)$ and chronic kidney disease-epidemiology collaboration (CKD-EPI) the lowest $\left(76 \pm 24 \mathrm{~mL} / \mathrm{min}\right.$ per $1.73 \mathrm{~m}^{2}$ ). Consequently, the Mayo formula classified more patients (56\%) as having normal renal function. There was a significant and strong correlation between the values obtained from all five formulas using Cockcroft-Gault as the reference formula: Mayo: $r=0.80, p<0.001$; CKD-EPI: $r=0.87, p<0.001$; modification of diet in renal disease (MDRD): $r=0.84, p<0.001$; inulin clearance-based: $r=0.99, p<0.001)$. Multivariable analysis demonstrated that decreased renal function is an independent predictor of 3-year mortality in all five formulas, with risk increasing by $15-25 \%$ for each 10 -unit decrease in eGFR. Despite the similarities between the formulas, the ability to predict mortality was highest in the Mayo formula and lowest in MDRD.

Conclusions: Our data suggest that while the Mayo formula is not currently recommended by any nephrology guidelines, it may be an alternative formula to predict mortality among patients with multivessel CAD, including to the widely used MDRD formula.
\end{abstract}

Keywords: Ischemic heart disease, Renal function, Glomerular filtration rate, Creatinine clearance

\section{Background}

Renal disease, particularly chronic kidney disease (CKD), is a common comorbidity in patients with ischemic heart disease, and is associated with worse short- and long-term clinical outcomes [1,2]. Patients with CKD demonstrate

\footnotetext{
* Correspondence: eilon.ram@sheba.health.gov.il

'Department of Cardiac Surgery, Leviev Cardiothoracic and Vascular Center, 52621 Tel Hashomer, Israel

${ }^{2}$ Sheba Medical Center, affiliated to the Sackler School of Medicine, Tel Aviv University, Tel Aviv, Israel

Full list of author information is available at the end of the article
}

accelerated atherosclerosis and increased risk for multivessel coronary artery disease (CAD), which is the most common cause of death in CKD patients [3]. Thus, an accurate definition of CKD status and staging is critical for risk stratification and management of CAD patients [4].

Renal function on admission, assessed by estimated glomerular filtration rate (eGFR) or creatinine clearance $(\mathrm{CrCl})$ is an independent predictor of both short- and long-term mortality in patients undergoing coronary revascularization [5].

C C The Author(s). 2021 Open Access This article is licensed under a Creative Commons Attribution 4.0 International License, which permits use, sharing, adaptation, distribution and reproduction in any medium or format, as long as you give appropriate credit to the original author(s) and the source, provide a link to the Creative Commons licence, and indicate if changes were made. The images or other third party material in this article are included in the article's Creative Commons licence, unless indicated otherwise in a credit line to the material. If material is not included in the article's Creative Commons licence and your intended use is not permitted by statutory regulation or exceeds the permitted use, you will need to obtain permission directly from the copyright holder. To view a copy of this licence, visit http://creativecommons.org/licenses/by/4.0/ The Creative Commons Public Domain Dedication waiver (http://creativecommons.org/publicdomain/zero/1.0/) applies to the data made available in this article, unless otherwise stated in a credit line to the data. 
There are a number of equations used for GFR estimation and CKD staging. For decades, the CockcroftGault (CG) equation was the most commonly used method for estimating kidney function. Recently, however, due to inherent limitations of the CG, several newer equations have been developed [6-8]. The Modification of Diet in Renal Disease (MDRD) and, more recently, the CKD Epidemiology Collaboration (CKD-EPI) equation, are the most extensively used of the newer formulas. The Mayo Clinic quadratic equation [9] and the inulin clearance-based (IB) eGFR equation [10] were developed in an attempt to better estimate GFR in patients with preserved kidney function.

Current literature fails in providing adequate data regarding the ability of these five formulas to predict outcomes in patients with multivessel CAD undergoing either percutaneous coronary intervention (PCI) or coronary artery bypass grafting (CABG). We aim to evaluate the performance of all five eGFR formulas in predicting 3-year all-cause mortality in a 'real-world' cohort of patients with multivessel CAD.

\section{Methods}

\section{Study design and population}

Patients were enrolled and prospectively followed-up in the Multivessel CAD Israeli Registry, details of which have been previously reported [11, 12]. In brief, this registry includes 1112 consecutive adult patients from the 22 hospitals in Israel that perform coronary angiography. All patients had multivessel CAD (Fig. S1). The study was approved by the Institutional Review Board of each of the participating centers and all patients provided informed consent.

\section{Assessing renal function}

We assessed five different eGFR formulas, based on the initial creatinine upon admission prior to pre-procedural hydration or contrast. The formulas used were: CG, MDRD, CKD-EPI, Mayo, and IB (Table 1) (http://www. israc.gov.il/?CategoryID $=242$ ).

Patients were categorized into five levels of renal function based on the calculated eGFR: no renal impairment $\left(>90 \mathrm{~mL} / \mathrm{min}\right.$ per $\left.1.73 \mathrm{~m}^{2}\right)$, mild renal dysfunction $\left(60-90 \mathrm{~mL} / \mathrm{min}\right.$ per $\left.1.73 \mathrm{~m}^{2}\right)$, moderate renal dysfunction $\left(30-59 \mathrm{~mL} / \mathrm{min}\right.$ per $\left.1.73 \mathrm{~m}^{2}\right)$, severe renal dysfunction $\left(15-29 \mathrm{~mL} / \mathrm{min}\right.$ per $\left.1.73 \mathrm{~m}^{2}\right)$ and kidney failure $\left(<15 \mathrm{~mL} / \mathrm{min}\right.$ per $\left.1.73 \mathrm{~m}^{2}\right)$. The US National Kidney Foundation criteria were adapted for significant renal dysfunction definition as an eGFR of $<60$ $\mathrm{mL} / \mathrm{min}$ per $1.73 \mathrm{~m}^{2}[13]$.
Table 1 Estimated glomerular filtration rate equations

\section{Cockcroft-Gault (CG) equation:}

[(140 - Age $) \times$ Weight $(\mathrm{kg}) \times(0.85$ if female $)] / 72 \times \mathrm{SCr}$ $\mathrm{SCr}$ in milligrams per deciliter

Modification of Diet in Renal Disease (MDRD) equation:

$186 \times \mathrm{SCr}^{-1.154} \times \mathrm{Age}^{-0.203} \times(1.201$ if black $) \times(0.742$ if female $)$

$\mathrm{SCr}$ in milligrams per deciliter

Chronic Kidney Disease Epidemiology Collaboration (CKD-EPI) equation:

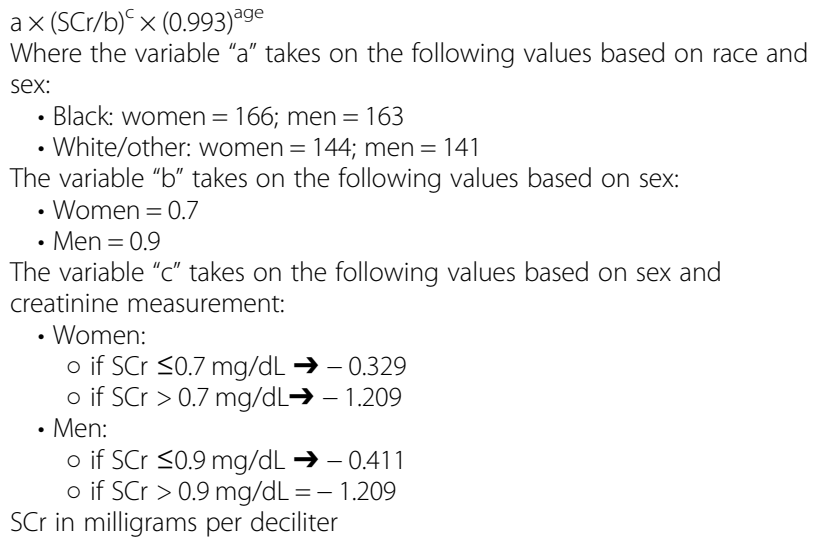

Mayo Clinic quadratic equation:

$\exp \left[1.911+5.249 / \mathrm{SCr}-2.114 / \mathrm{SCr}^{2}-0.00686 \times\right.$ Age $-(0.205$ if female)

If $\mathrm{SCr}<0.8 \mathrm{mg} / \mathrm{dL}$ than $\mathrm{SCr}=0.8$.

$\mathrm{SCr}$ in micromolar

Inulin clearance-based (IB) eGFR equation:

$[(155-$ Age $) \times$ Weight $(\mathrm{kg}) / \mathrm{Scr}] \times(0.85$ if female)

$\mathrm{SCr}$ in micromolar

$\mathrm{SCr}$ Serum creatinine (in milligrams per deciliter)

\section{Statistical Analysis}

Data are presented as mean \pm standard deviation. Categorical variables are given as frequencies and percentages. A chi-square test was used for comparison of categorical variables between different renal function groups. Student's t-test was performed for comparison of continuous variables.

The correlation between CG, MDRD, Mayo, IB and CKD-EPI formulas was tested using Pearson's correlation coefficient. We performed a Bland and Altman analysis to assess the agreement between values derived from each of the other formulas and the values obtained from the CG formula.

Survival analysis was done using the Kaplan-Meier method, and statistical differences between predefined renal dysfunction groups were tested using the logrank test. Multivariate Cox proportional hazard modeling was used to identify factors associated with mortality risk at follow-up. Candidate factors appear in Table 2.

To evaluate the ability of the formulas to predict all-cause mortality, we estimated receiver operating characteristic (ROC) curves and area under the curve 
Table 2 Patient characteristics by the renal function categories

\begin{tabular}{|c|c|c|c|c|}
\hline & eGFR $\leq 60(N=126)$ & Discordant eGFR $(N=203)$ & eGFR > $60(N=783)$ & $p$-value \\
\hline Age (years) (mean $\pm S D$ ) & $74 \pm 10$ & $73 \pm 9$ & $62 \pm 10$ & $<0.001$ \\
\hline Gender (male) (\%) & $86(68)$ & $136(67)$ & $663(85)$ & $<0.001$ \\
\hline Hypertension (\%) & 119 (94) & $170(84)$ & $530(68)$ & $<0.001$ \\
\hline Previous PCI (\%) & $45(36)$ & $75(37)$ & $267(34)$ & 0.751 \\
\hline COPD (\%) & $11(9)$ & $20(10)$ & $47(6)$ & 0.116 \\
\hline Diabetes (\%) & $82(65)$ & $98(48)$ & $321(41)$ & $<0.001$ \\
\hline Hemodialysis (\%) & $5(4)$ & $0(0)$ & $0(0)$ & $<0.001$ \\
\hline Hyperlipidemia (\%) & $102(82)$ & $152(76)$ & $562(73)$ & 0.087 \\
\hline Smoking (\%) & $19(15)$ & $40(20)$ & $236(30)$ & $<0.001$ \\
\hline CHF (\%) & $23(19)$ & $29(14)$ & $64(8)$ & $<0.001$ \\
\hline Prior CVA/TIA (\%) & $16(13)$ & $36(18)$ & $51(6)$ & $<0.001$ \\
\hline Atrial fibrillation (\%) & $12(10)$ & $24(12)$ & $46(6)$ & 0.008 \\
\hline SYNTAX score (mean \pm SD) & $23 \pm 9$ & $24 \pm 11$ & $22 \pm 10$ & 0.026 \\
\hline Body mass index $\left(\mathrm{Kg} / \mathrm{m}^{2}\right)($ mean $\pm \mathrm{SD})$ & $28 \pm 4.7$ & $28.3 \pm 7.1$ & $28.9 \pm 5.1$ & 0.138 \\
\hline \multicolumn{5}{|l|}{ Medical treatment } \\
\hline Aspirin (\%) & $93(77)$ & $149(76)$ & $519(70)$ & 0.121 \\
\hline Beta blockers (\%) & $82(66)$ & $122(60)$ & $367(48)$ & $<0.001$ \\
\hline ACE-I (\%) & $62(49)$ & $97(48)$ & $343(45)$ & 0.488 \\
\hline Statins (\%) & $97(78)$ & $150(74)$ & $514(67)$ & 0.012 \\
\hline Anti-hyperglycemic (\%) & $41(37)$ & $62(34)$ & $206(29)$ & 0.184 \\
\hline \multicolumn{5}{|l|}{ Laboratory on admission } \\
\hline Hemoglobin (mean \pm SD) & $12 \pm 1.7$ & $13.1 \pm 1.7$ & $13.9 \pm 1.6$ & $<0.001$ \\
\hline Urea $($ mean $\pm S D)$ & $62.7 \pm 49.8$ & $32.6 \pm 17.3$ & $27 \pm 13.2$ & $<0.001$ \\
\hline Creatinine (mean $\pm S D$ ) & $2.57 \pm 2.21$ & $1.17 \pm 0.2$ & $0.87 \pm 0.19$ & $<0.001$ \\
\hline $\mathrm{HbA} 1 \mathrm{C}($ mean $\pm \mathrm{SD})$ & $7.4 \pm 2.1$ & $6.7 \pm 1.6$ & $7.1 \pm 2$ & 0.322 \\
\hline Ethnicity & & & & 0.192 \\
\hline Israeli Jews (\%) & $107(85)$ & $174(86)$ & $613(78)$ & \\
\hline Israeli Arabs (\%) & $19(15)$ & $29(14)$ & $156(20)$ & \\
\hline Others (\%) & $0(0)$ & $0(0)$ & $13(2)$ & \\
\hline
\end{tabular}

eGFR Estimated glomerular filtration rate, SD Standard deviation, $P C I$ Percutaneous coronary intervention, COPD Chronic obstruction pulmonary disease, CHF Congestive heart failure, CVA Cerebrovascular accident, TIA Transient ischemic attack, ACE-I Angiotensin converting enzyme inhibitor

(AUC) with 95\% confidence interval (CI) using corresponding logistic models. Hosmer-Lemeshow goodness-of-fit test was used to assess model suitability. Furthermore, to predict the benefit incurred by the addition of a GFR formula to a baseline model of mortality prediction, we estimated net reclassification improvement (NRI) and integrated discrimination improvement (IDI). Using binary logistic regression, we computed predicted risk for 3-year mortality from a baseline model without GFR (age, diabetes, history of congestive heart failure, atrial fibrillation, previous stroke, SYNTAX score, chronic obstructive pulmonary disease, hypertension, sex) and a similar model that included GFR (for each formula separately). For calculation of the NRI, rescaled individual predicted risk from baseline and GFR models were compared in three pre-specified risk thresholds; low $(<10 \%)$, intermediate $(10-20 \%)$ and high risk $(>=20 \%)$. IDI and relative IDI were computed similarly to NRI, albeit without pre-specified risk thresholds.

Statistical significance was assumed when the null hypothesis could be rejected at $P<0.05$. All $P$-values are the results of two-sided tests. Statistical analyses were conducted using R (version 3.4.1).

\section{Results}

Baseline study population characteristics

The mean age of the cohort was $66 \pm 11$ years, with a male majority of $80 \%$. Among the 1112 patients with multivessel CAD included in the registry, $126(11.3 \%)$ 
had significant renal impairment (GFR $\leq 60 \mathrm{~mL} / \mathrm{min}$ per $1.73 \mathrm{~m}^{2}$ ) according to all five formulas (MDRD, Mayo, CKD-EPI, CG, and IB formulas), and 783 (70.4\%) had non-significant renal impairment (GFR > $60 \mathrm{~mL} / \mathrm{min}$ per $1.73 \mathrm{~m}^{2}$ ) according to all five formulas. Of the remaining 203 patients (18.3\%), the eGFR was discordant and shifted between $<60 \mathrm{~mL} / \mathrm{min}$ per $1.73 \mathrm{~m}^{2}$ and $>60 \mathrm{~mL} / \mathrm{min}$ per $1.73 \mathrm{~m}^{2}$ depending on the formula used. "Discordant eGFR" was used when a patient was considered to have normal renal function by at least one formula and abnormal renal function by at least one formula. Patients with normal renal function tended to be younger with fewer cardiovascular risk factors such as diabetes, hypertension, history of stroke, history of congestive heart failure, atrial fibrillation and lower SYNTAX scores (Table 2). There were 5 patients on hemodialysis prior to intervention, all were in the significant renal impairment group, and all underwent revascularization by CABG.

CABG was used as the revascularization strategy in $50 \%$ of the significant renal impairment group, $51 \%$ of the discordant group and $54 \%$ of the non-significant renal impairment group. Compared with PCI patients, those who underwent CABG were more likely to be male ( $83 \%$ vs. $77 \%, p=0.013)$, had a higher frequency of diabetes $(49 \%$ vs. $42 \%, p=0.026)$, and were more likely to have had a prior stroke $(12 \%$ vs. $7 \%, p=$ 0.014). Those who underwent CABG also had higher mean SYNTAX scores $(27 \pm 9$ vs. $18 \pm 8, p<0.001)$, reflective of more complex CAD. However, PCItreated patients were more likely to have had prior PCI $(40 \%$ vs. $30 \%, p=0.001)$, prior myocardial infarction (32\% vs. $25 \%, p=0.007)$ and a history of congestive heart failure $(12 \%$ vs. $8 \%, p=0.046)$, than those treated with CABG.

\section{Estimated glomerular filtration rate}

With all five formulas, only a minority of patients had severe renal impairment or kidney failure. The prevalence of patients with renal failure (eGFR $<60 \mathrm{ml} / \mathrm{min}$ / $1.73 \mathrm{~m}^{2}$ ) at baseline was $12.9 \%$ by the Mayo equation,
$20.9 \%$ by MDRD, $22.8 \%$ by CG, $22.9 \%$ by IB and $24.6 \%$ by the CKD-EPI equation.

The mean eGFR values on admission were in the mild renal dysfunction range for both CABG and PCI patients with no differences in eGFR between the two groups (Fig. S2). For both CABG and PCI patients, the Mayo formula yielded the highest mean value $(89.8 \pm 27.1$ and $90.6 \pm 25.4 \mathrm{~mL} / \mathrm{min}$ per $1.73 \mathrm{~m}^{2}, p=0.623$; respectively) and CKD-EPI the lowest $(75.4 \pm 24.7$ and $76.6 \pm 23.4 \mathrm{~mL} /$ $\min$ per $1.73 \mathrm{~m}^{2}, p=0.402$; respectively). Notably, the Mayo included more patients with normal renal function $(N=625,56 \%)$ and thus fewer with mild $(N=343,31 \%)$ and moderate renal dysfunction $(N=103,9 \%)$ (Fig. S2, Table 3). This finding was consistent in both the CABG and PCI subgroups.

In order to determine whether the CG method, as the reference formula, and the Mayo, CKD-EPI, MDRD, and IB formulas yielded the same results, we calculated the correlation coefficient, and found a strong correlation between the CG formula and each of the other four formulas (Mayo: $r=0.80, p<0.001$; CKD-EPI: $r=0.87, p<$ 0.001; MDRD: $r=0.84, p<0.001$; IB: $r=0.99, p<0.001$ ). Furthermore, in order to assess the agreement between the values obtained from the CG formula and those from each of the other formulas we used the Bland and Altman analyses, which showed good agreement with all formulas used (Fig. 1a-d). The mean \pm SD of the eGFR difference between the CG formula (reference) and the Mayo, CKD-EPI, MDRD, and IB formulas were: $2 \pm 21.7$, $12.2 \pm 19.2,5.4 \pm 19.9$, and $1.8 \pm 4.1 \mathrm{~mL} / \mathrm{min}$ per $1.73 \mathrm{~m}^{2}$, respectively.

\section{Mortality by renal function and post-procedural acute kidney injury}

Post-procedural acute kidney injury was more prevalent in the CABG than the PCI group $(5.8 \%$ vs. $0.9 \%, p<$ 0.001 ), and more in the eGFR $\leq 60 \mathrm{~mL} / \mathrm{min}$ per $1.73 \mathrm{~m}^{2}$ than the discordant and eGFR $>60$ groups $(9.7 \%$ vs. $3.9 \%$ vs. $1.7 \%, p<0.001)$.

Patients with eGFR $\leq 60 \mathrm{~mL} / \mathrm{min}$ per $1.73 \mathrm{~m}^{2}$ by all five methods had significantly higher 30-day, 1-year and 3-

Table 3 Distribution of eGFR according to the five different formulas

\begin{tabular}{|c|c|c|c|c|c|}
\hline & CKD-EPI & MDRD & Mayo & IB & CG \\
\hline Mean eGFR (mean $\pm S D)$ & $76 \pm 24$ & $83 \pm 32$ & $90 \pm 26$ & $86 \pm 35$ & $88 \pm 36$ \\
\hline eGFR $>90$ & $359(32 \%)$ & $397(36 \%)$ & $625(56 \%)$ & $464(42 \%)$ & $490(44 \%)$ \\
\hline eGFR 60-90 & $480(43 \%)$ & 483 (44\%) & $343(31 \%)$ & 393 (35\%) & $369(33 \%)$ \\
\hline eGFR 30-59 & $224(20 \%)$ & $191(17 \%)$ & $103(9 \%)$ & $215(19 \%)$ & $212(19 \%)$ \\
\hline eGFR 15-29 & $27(2 \%)$ & $16(1 \%)$ & $18(2 \%)$ & $25(2 \%)$ & $26(2 \%)$ \\
\hline eGFR $<15$ & $19(2 \%)$ & $18(2 \%)$ & $20(2 \%)$ & $14(1 \%)$ & $14(1 \%)$ \\
\hline
\end{tabular}

eGFR Estimated glomerular filtration rate, SD Standard deviation, CKD-EPI Chronic kidney disease epidemiology collaboration, MDRD Modification of diet in renal disease, IB Inulin clearance-based equation, CG Cockcroft-Gault 

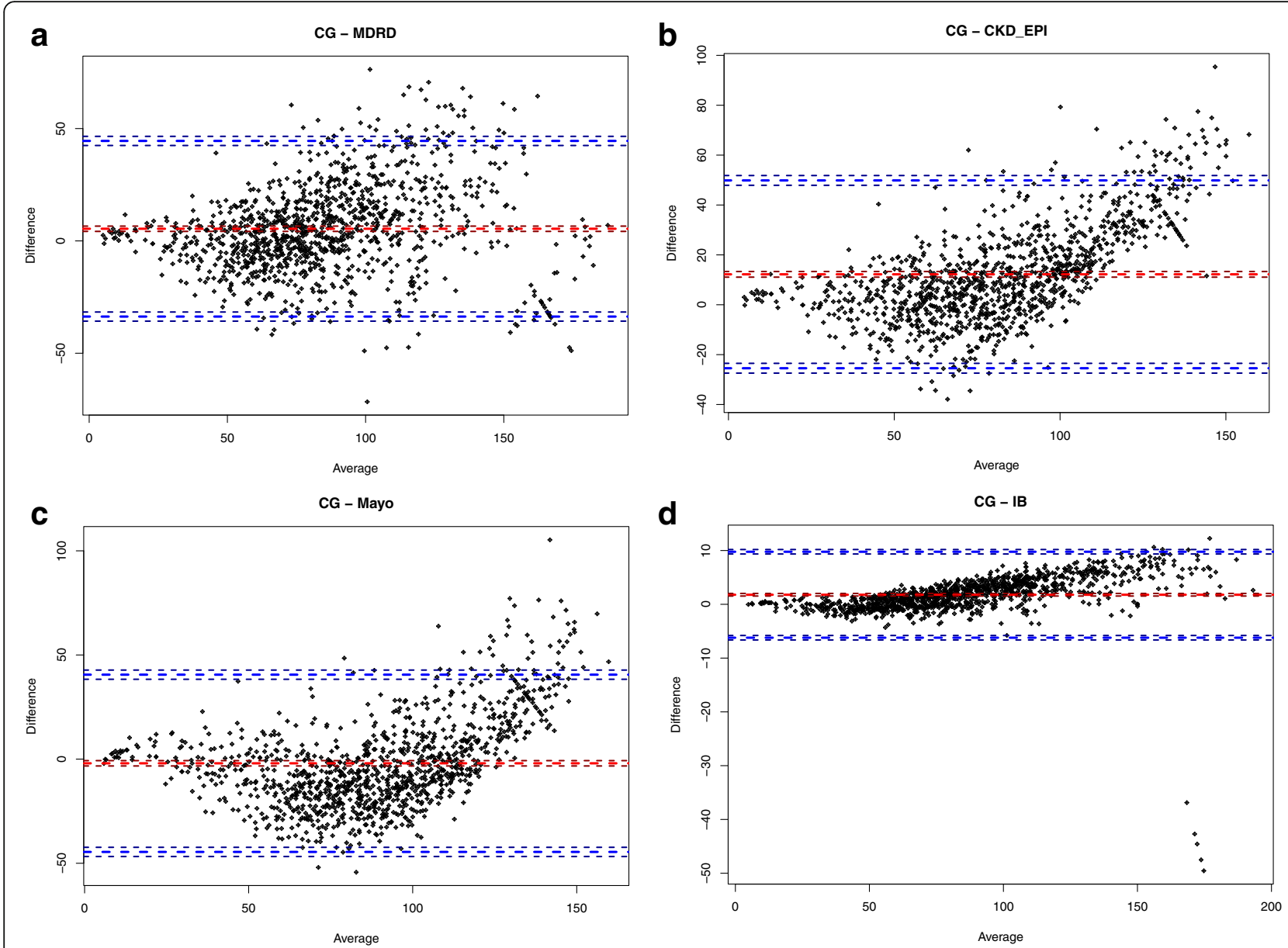

Fig. 1 Bland and Altman analysis to assess the agreement between values derived from each formula compared with the CG formula. Red line is for the mean difference and blue lines are for \pm 1.96 SD. CG = Cockcroft-Gault; MDRD = Modification of Diet in Renal Disease; CKD-EPI=Chronic Kidney Disease Epidemiology Collaboration; IB=Inulin clearance-based equation; SD = Standard deviation

year mortality compared to patients with discordant eGFR, and compared to patients with eGFR $>60 \mathrm{~mL} /$ min per $1.73 \mathrm{~m}^{2}$ by all five methods $(5.8 \%$ vs. $2.6 \%$ vs. $0 \%, p<0.001 ; 18.8 \%$ vs. $8.2 \%$ vs. $2.1 \%, p<0.001$; and $27 \%$ vs. $12.3 \%$ vs. $4.7 \%, p<0.001$, respectively) (Fig. $2 \mathrm{a}$ and Fig. S3). Sub-analysis among CABG and PCI separately revealed similar result (Fig. 2b-c). There were no significant differences in 3-year mortality rates between patients who underwent either CABG or PCI in all three eGFR categories (consistently low eGFR $25 \%$ vs. 29\%, log-rank $p=0.879$; discordant eGFR $11 \%$ vs. $14 \%$, logrank $p=0.714$; consistently high eGFR $3 \%$ vs. $6 \%$, logrank $p=0.121$; respectively). The overall 3 -year mortality rates were not significantly different between the CABG and PCI groups $(7.4 \%$ vs. 9.7\%, log-rank $p=0.294)$. However, the severity of renal impairment correlated with increased mortality (Fig. 3). Multivariable analysis demonstrated that worse renal function is an independent predictor of 3-year mortality for all five formulas (Table 4). Mortality risk was increased by $16-28 \%$ for each 10-unit decrease in eGFR, using all five formulas. Other independent predictors of 3-year mortality were older age, chronic obstructive pulmonary disease, previous stroke, history of atrial fibrillation and diabetes.

The ability of the five formulas to predict 3-year mortality risk was highest with the Mayo (AUC 0.78 [0.73$0.83]$ ) and lowest with the MDRD formula (AUC 0.75 $[0.70-0.80]) \quad(p=0.004)$. The $p$-value of HosmerLemeshow test was $>0.05$ for all models, indicating that they were suitable. The NRI results showed that addition of a GFR formula to the baseline model correctly reclassified approximately one-sixth of patients to a higher predicted risk group (Table 5). IDI analysis demonstrated that, when added to the basic logistic regression model, each of the five formulas improved mortality risk prediction. Among the five formulas, the Mayo had the highest additive effect on mortality prediction (Mayo: $\mathrm{rIDI}=26.4 \%, p=0.001 ; \mathrm{CG}: \mathrm{rIDI}=16.6 \%, p=0.009 ; \mathrm{IB}:$ $\mathrm{rIDI}=15.2 \%, \quad p=0.012 ; \quad$ CKD-EPI: $\quad$ IIDI $=22.8 \%, \quad p=$ 0.003; and MDRD: IDI $=11.7 \%, p=0.035)$ (Table 5). 


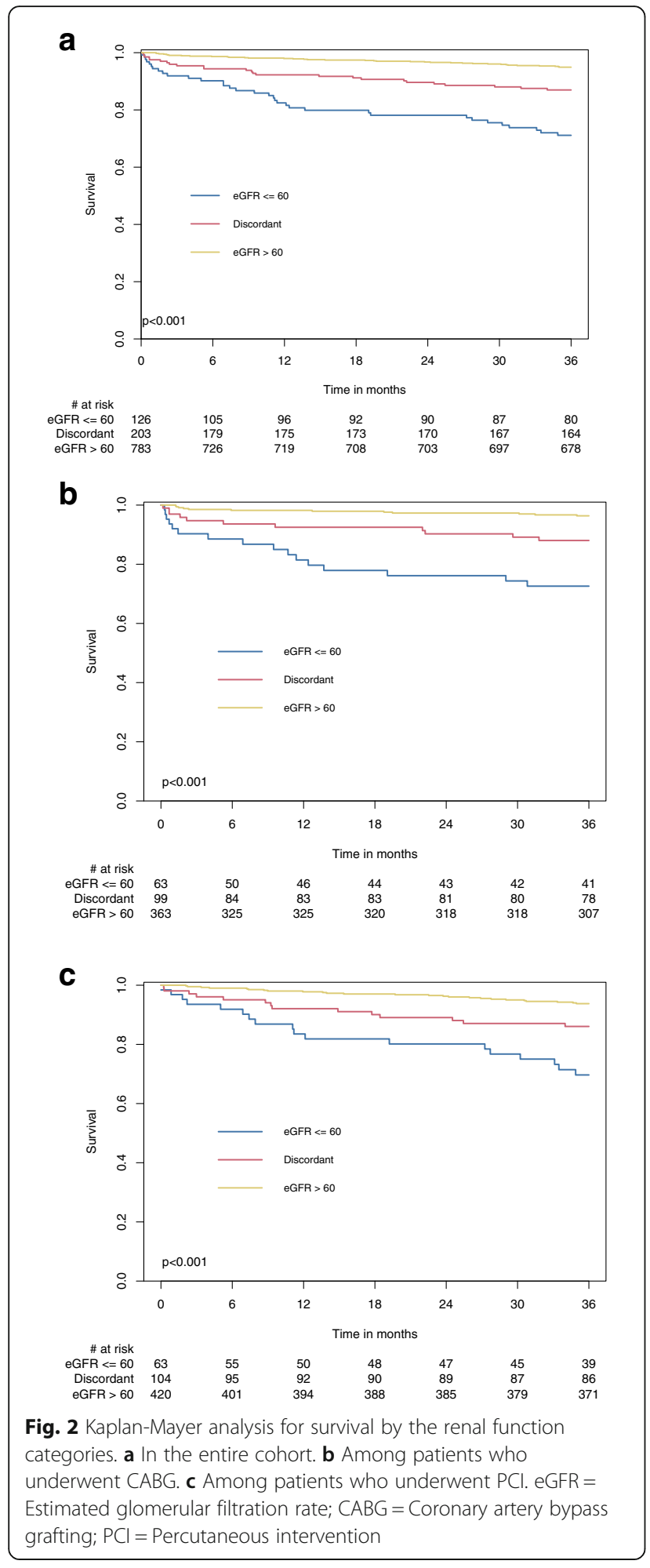

\section{Discussion}

This prospective multicenter national registry study describes several cardinal findings regarding evaluation of renal function in patients with multivessel CAD who are referred for revascularization in a 'real- world' setting. We have shown that: (1) patients with multivessel $\mathrm{CAD}$ and significant renal dysfunction demonstrate increased 3-year mortality; (2) despite the significant and strong correlation between eGFR values using all five formulas, the proportion of patients categorized into the different renal function groups varied considerably, suggesting a significant clinical impact of the GFR formula used; (3) mortality increased as renal function worsened in all renal function categories; (4) patients whose renal dysfunction status shifted from significant to nonsignificant or vice versa using the different formulas, had mortality rates that were intermediate between those with and without significant renal dysfunction. This suggests that the discordance between the formulas may result from differences in clinically relevant parameters, such as age and weight; and (5) although the MDRD formula is used extensively in clinical practice, it is less accurate in predicting mortality relative to other formulas in patients with multivessel CAD.

The 2011 European Society of Cardiology (ESC) guidelines recommended the MDRD and GC formulas for assessment of renal function in CAD patients [14]. However, according to more recent 2015 ESC guidelines, there is no recommended formula [15]. The CKD-EPI formula is considered the gold standard for eGFR by the 2012 Kidney Disease Improving Global Outcomes guidelines (KDIGO) [16]. In this study, the rate of renal impairment varied from 13 to $25 \%$ depending on the formula used, with the choice of formula influencing patient stratification into different renal function categories. We showed that despite this variability in eGFR using different formulas, renal dysfunction remained an independent predictor for mortality with all five formulas. Nevertheless, the absolute mortality rates varied for each renal function category using the different formulas.

Numerous studies have compared the five eGFR formulas outlining important observations. Lin et al. found that the MDRD is more accurate for eGFR calculation in healthy or mildly impaired renal function adults compared with the CG formula [17]. Matsushita et al. showed that the CKD-EPI equation classified fewer individuals as having renal dysfunction and more accurately categorized the risk for mortality than did the MDRD equation [18]. In contrast, however, Carter suggested that the CKD-EPI formula may actually over-estimate renal dysfunction prevalence in elderly patients and showed scarce differences between the CKD-EPI and MDRD formulas [19]. Willems et al. showed that the CG and MDRD formulas effectively predicted mortality, whereas the CKD-EPI formula did not [20]. A recent study by Jo et al. 

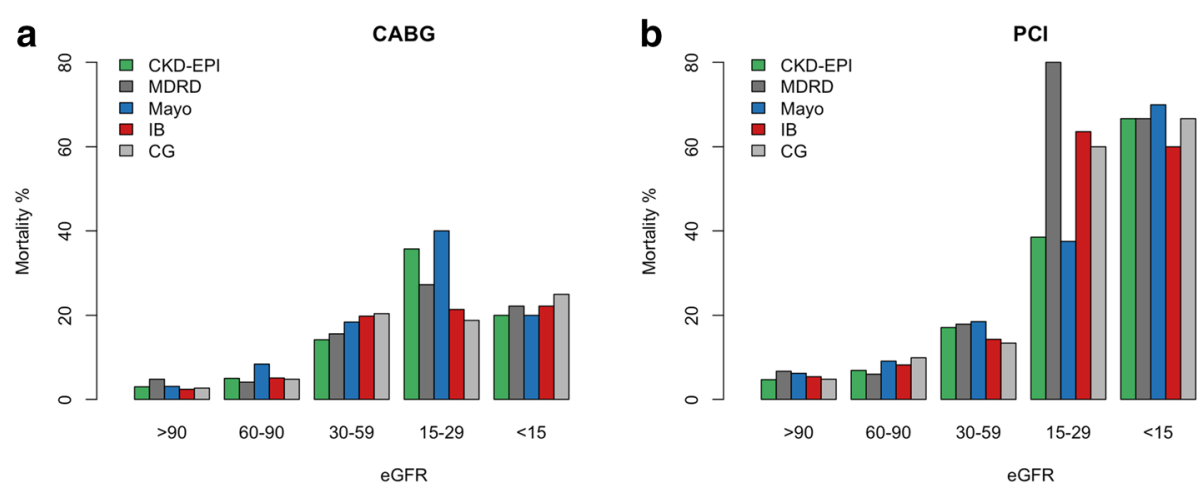

Fig. 3 Three-year mortality rates based on renal function status according to the five different formulas. a Among patients who underwent CABG. b Among patients who underwent PCI. eGFR = Estimated glomerular filtration rate; CKD-EPI=Chronic kidney disease epidemiology collaboration; MDRD = Modification of diet in renal disease; $I B=$ Inulin clearance-based equation; $C G=$ Cockcroft-Gault; $C A B G=$ Coronary artery bypass grafting; $\mathrm{PCl}=$ Percutaneous intervention

showed that the Mayo equation was the most accurate in predicting post-operative acute kidney injury when comparing the five eGFR formulas in 4125 adult patients undergoing elective cardiovascular surgery [21]. Fu et al. showed that among 1050 patients aged $>60$ years with CAD, the CKD-EPI and Mayo equations were significantly superior to the MDRD in predicting 1year mortality, and the Mayo demonstrated mild superiority over the CKD-EPI equation [22].

Our analysis showed that the Mayo formula offered the most accurate mortality prediction in CAD patients undergoing revascularization, thus confirming the results of previous studies [22]. This finding can be explained by the coefficients and variables included in the equations. As both older age and lower body weight are well-known predictors of outcome in patients with $\mathrm{CAD}$, it follows that a formula accounting

Table 4 Predictors for 3-year mortality ${ }^{a}$. A univariable and multivariable analysis

\begin{tabular}{lllllllll}
\hline Formula & \multicolumn{3}{l}{ Univariable analysis } & & \multicolumn{3}{c}{ Multivariable analysis } \\
\cline { 2 - 3 } & HR & $\mathbf{9 5 \%} \mathbf{~ C l}$ & $\boldsymbol{p}$-value & & HR & $\mathbf{9 5 \% ~ C l}$ & $\boldsymbol{p}$-value \\
\hline CKD_EPI & 1.35 & $1.25-1.45$ & $<0.001$ & & 1.28 & $1.16-1.41$ & $<0.001$ \\
MDRD & 1.24 & $1.15-1.32$ & $<0.001$ & & 1.16 & $1.07-1.27$ & 0.001 \\
Mayo & 1.30 & $1.22-1.37$ & $<0.001$ & & 1.24 & $1.14-1.35$ & $<0.001$ \\
IB & 1.27 & $1.18-1.35$ & $<0.001$ & & 1.18 & $1.08-1.29$ & $<0.001$ \\
CG & 1.35 & $1.25-1.45$ & $<0.001$ & & 1.28 & $1.16-1.41$ & $<0.001$
\end{tabular}

$H R$ Hazard ratio, Cl Confidence interval, CKD-EPI Chronic kidney disease epidemiology collaboration, MDRD Modification of diet in renal disease, $I B$ Inulin clearance-based equation, CG Cockcroft-Gault, eGFR Estimated glomerular filtration rate, CVA Cerebrovascular accident, TIA Transient ischemic attack, COPD Chronic obstruction pulmonary disease

aHazard ratios with $95 \%$ Cl's for 3-year mortality (for 10-unit decrements in eGFR)

${ }^{\mathrm{b}}$ The covariates included in the model were: age, gender, diabetes, congestive heart failure, history of CVA/TIA, SYNTAX score, atrial fibrillation, hypertension, COPD and post-procedure acute kidney injury for these factors would more accurately predict mortality. While the Mayo formula was found to accurately predict mortality in our cohort, it is less widely used, has not been validated in diverse populations and is not currently recommended by any nephrology practice guidelines. Furthermore, previous reports have shown that the Mayo equation proved inaccurate in type-2 diabetic patients with hyperfiltration [23] or normal renal function [24] and in the very elderly $[25,26]$.

Interestingly, we have shown that in a 'real-world' setting the choice of GFR, as reflected by the different categories (consistently low, discordant and consistently high eGFR), did not affect decision-making regarding the revascularization approach. Indeed, we did not detect any significant difference in the 3-year all-cause mortality by the different revascularization strategies.

\section{Limitations}

This study was based on a national prospective observational registry of patients admitted for multivessel CAD. As such, bias in treatment decision cannot be excluded. Another limitation is the lack of available data on renal dysfunction duration. While our results were adjusted for possible confounding variables, residual confounding cannot be excluded, and the lack of adjustment for variables not captured in the registry may represent a limitation. Data regarding other outcomes such as recurrent myocardial infarction, recurrent revascularization and renal function during the follow-up period were unavailable. Analysis of cardiac events could reinforce the conclusion that significant renal dysfunction upon admission is associated with late cardiac events. 
Table 5 Discrimination analysis for 3-year mortality according to different GFR formulas

\begin{tabular}{lllllll}
\hline Formula & ROC & Hosmer-Lemeshow test & AIC & NRI & IDI & rIDI \\
\hline MDRD & $0.75(0.70-0.80)$ & $x^{2}=6.8, p=0.553$ & 592.2 & $14.1 \%(4.1-24.1 \%), p=0.006$ & $0.011(0-0.021), p=0.035$ & $11.7 \%$ \\
CKD-EPI & $0.76(0.71-0.82)$ & $x^{2}=9.6, p=0.295$ & 581.9 & $19.2 \%(7.9-30.5 \%), p=0.001$ & $0.025(0.008-0.041), p=0.003$ & $22.8 \%$ \\
Mayo & $0.78(0.73-0.83)$ & $x^{2}=18.2, p=0.644$ & 578.3 & $15 \%(3.6-26.4 \%), p=0.011$ & $0.03(0.011-0.048), p=0.001$ & $26.4 \%$ \\
IB & $0.76(0.71-0.81)$ & $x^{2}=10.6, p=0.225$ & 589.4 & $16.1 \%(6-26.1 \%), p=0.002$ & $0.015(0.003-0.027), p=0.012$ & $15.2 \%$ \\
CG & $0.76(0.70-0.81)$ & $x^{2}=11.2, p=0.190$ & 587.8 & $17.3 \%(6.9-27.6 \%), p=0.001$ & $0.016(0.004-0.029), p=0.009$ & $16.6 \%$
\end{tabular}

GFR Glomerular filtration rate, ROC Receiver operating characteristic, AIC Akaike information criterion, NRI Net reclassification improvement, IDI Integrated discrimination improvement, rIDI Relative integrated discrimination improvement, MDRD Modification of diet in renal disease equation, CKD-EPI Chronic kidney disease epidemiology collaboration equation, IB Inulin clearance-based equation, CG Cockcroft-Gault equation

\section{Conclusions}

In patients with multivessel CAD who undergo revascularization with either CABG or PCI, significant renal dysfunction upon admission is associated with mortality, regardless of the eGFR formula used. While the Mayo formula is not currently recommended by any nephrology guidelines, our data suggest that it may be an alternative formula to predict mortality among patients with multivessel CAD. These findings have important implications for everyday clinical practice in risk stratification and management of CAD patients.

\section{Abbreviations}

AUC: Area under the curve; CABG: Coronary artery bypass grafting; CAD: Coronary artery disease; CG: Cockcroft-Gault; Cl: Confidence interval; CKD: Chronic kidney disease; CKD-EPI: Chronic kidney disease Epidemiology Collaboration; $\mathrm{CrCl}$ : Creatinine clearance; eGFR: Estimated glomerular filtration rate; IB: Inulin clearance-based; MDRD: Modification of Diet in Renal Disease; NRI: Net reclassification improvement; $\mathrm{PCl}$ : Percutaneous coronary intervention; rIDI: Relative integrated discrimination improvement; ROC: Receiver operating characteristic

\section{Supplementary Information}

The online version contains supplementary material available at https://doi. org/10.1186/s13019-021-01502-1.

Additional file 1: Figure S1. Flow chart summary from consent and eligibility, through a 3-year follow-up. CAD = Coronary artery disease; $\mathrm{PCl}=$ Percutaneous coronary intervention; $\mathrm{CABG}=$ Coronary artery bypass grafting

Additional file 2: Figure S2. Distribution of CKD stages determined by eGFR according to the five different formulas. A - Among patients who underwent $C A B G$. B - Among patients who underwent PCI. CKD = Chronic kidney disease; eGFR = estimated glomerular filtration rate; $\mathrm{CABG}=$ coronary artery bypass grafting; $\mathrm{PCl}=$ percutaneous coronary intervention; CKD-EPI = Chronic Kidney disease Epidemiology Collaboration; MDRD = Modification of Diet in Renal Disease; $\mathrm{IB}=$ Inulin clearance-Based equation; CG = Cockcroft-Gault

Additional file 3: Figure S3. Kaplan-Mayer analysis for survival by the renal function categories by the different eGFR formulas. eGFR = Estimated glomerular filtration rate; $\mathrm{MDRD}=$ Modification of Diet in Renal Disease; CKD-EPI = Chronic Kidney disease Epidemiology Collaboration; $\mathrm{IB}=$ Inulin clearance-Based equation; $\mathrm{CG}=$ Cockcroft-Gault

\section{Acknowledgements}

Not applicable.

\section{Authors' contributions}

ER analyzed and interpreted the patient data and wrote the research project and the full manuscript. PB performed study revision and editing. AS performed study revision and editing. NS performed data collection and interpretation. AAL performed study revision and editing. LS performed study revision and editing. ER analyzed and interpreted the data and wrote the full manuscript. All authors read and approved the final manuscript.

Funding

Not applicable.

\section{Availability of data and materials}

The datasets used and/or analyzed during the current study are available from the corresponding author on reasonable request.

\section{Declarations}

Ethics approval and consent to participate

The study was approved by the Institutional Review Board of each of the participating centers.

\section{Consent for publication}

All patients provided informed consent.

\section{Competing interests}

The authors declare that they have no competing interests.

\section{Author details}

${ }^{1}$ Department of Cardiac Surgery, Leviev Cardiothoracic and Vascular Center, 52621 Tel Hashomer, Israel. ${ }^{2}$ Sheba Medical Center, affiliated to the Sackler School of Medicine, Tel Aviv University, Tel Aviv, Israel. ${ }^{3}$ Department of Nephrology, Leviev Cardiothoracic and Vascular Center, 52621 Tel Hashomer, Israel. ${ }^{4}$ Department of Cardiology, Leviev Cardiothoracic and Vascular Center, 52621 Tel Hashomer, Israel. ${ }^{5}$ Maccabi Health Services, Tel Aviv, Israel.

Received: 14 October 2020 Accepted: 19 April 2021

Published online: 01 May 2021

\section{References}

1. Volodarskiy A, Kumar S, Amin S, Bangalore S. Optimal treatment strategies in patients with chronic kidney disease and coronary artery disease. Am J Med. 2016:129(12):1288-98. https://doi.org/10.1016/j.amjmed.2016.06.046.

2. Engelbertz C, Reinecke H, Breithardt G, Schmieder RE, Fobker M, Fischer D, et al. Two-year outcome and risk factors for mortality in patients with coronary artery disease and renal failure: the prospective, observational CAD-REF registry. Int J Cardiol. 2017;243:65-72. https://doi.org/10.1016/j.ijca rd.2017.05.022.

3. Herzog CA, Asinger RW, Berger AK, Charytan DM, Diez J, Hart RG, et al. Cardiovascular disease in chronic kidney disease. A clinical update from kidney disease: improving global outcomes (KDIGO). Kidney Int. 2011;80(6): 572-86. https://doi.org/10.1038/ki.2011.223.

4. Marenzi G, Cosentino N, Guastoni C. How to balance risks and benefits in the management of CKD patients with coronary artery disease. J Nephrol. 2015;28(4):403-13. https://doi.org/10.1007/s40620-015-0184-2.

5. Pocock S, Bueno H, Licour M, Medina J, Zhang L, Annemans L, et al. Predictors of one-year mortality at hospital discharge after acute coronary syndromes: a new risk score from the EPICOR (long-tErm follow uP of antithrombotic management patterns in acute CORonary syndrome patients) study. Eur Heart J Acute Cardiovasc Care. 2015:4(6):509-17. https:// doi.org/10.1177/2048872614554198. 
6. Levey AS, Bosch JP, Lewis JB, Greene T, Rogers N, Roth D. A more accurate method to estimate glomerular filtration rate from serum creatinine: a new prediction equation. Modification of diet in renal disease study group. Ann Intern Med. 1999;130(6):461-70. https://doi.org/10.7326/0003-4819-130-6-1 99903160-00002

7. Levey AS, Coresh J, Greene T, Marsh J, Stevens LA, Kusek JW, et al. Expressing the modification of diet in renal disease study equation for estimating glomerular filtration rate with standardized serum creatinine values. Clin Chem. 2007;53(4):766-72. https://doi.org/10.1373/clinchem.2006.077180.

8. Levey AS, Stevens LA, Schmid CH, Zhang YL, Castro AF 3rd, Feldman $\mathrm{HI}$, et al. A new equation to estimate glomerular filtration rate. Ann Intern Med. 2009;150(9):604-12. https://doi.org/10.7326/0003-4819-1509-200905050-00006.

9. Rigalleau V, Lasseur C, Raffaitin C, Perlemoine C, Barthe N, Chauveau P, et al. The Mayo Clinic quadratic equation improves the prediction of glomerular filtration rate in diabetic subjects. Nephrol Dial Transplant. 2007;22(3):813-8. https://doi.org/10.1093/ndt/gfl649.

10. Rule AD, Larson TS, Bergstralh EJ, Slezak JM, Jacobsen SJ, Cosio FG. Using serum creatinine to estimate glomerular filtration rate: accuracy in good health and in chronic kidney disease. Ann Intern Med. 2004;141(12):929-37. https://doi.org/10.7326/0003-4819-141-12-200412210-00009.

11. Ram E, Goldenberg I, Kassif Y, Segev A, Lavee J, Einhorn-Cohen M, et al. Real-life characteristics and outcomes of patients who undergo percutaneous coronary intervention versus coronary artery bypass grafting for left main coronary artery disease: data from the prospective multi-vessel coronary artery disease (MULTICAD) Israeli registry. Eur J Cardiothorac Surg. 2018;54(4):717-23.

12. Ram E, Goldenberg I, Kassif Y, Segev A, Lavee J, Shlomo N, et al. Comparison of patients with multivessel disease treated at centers with and without on-site cardiac surgery. J Thorac Cardiovasc Surg. 2018;155(3):86573 e3. https://doi.org/10.1016/j.jtcvs.2017.09.144.

13. Stevens PE, Levin A. Kidney disease: improving global outcomes chronic kidney disease guideline development work group M. evaluation and management of chronic kidney disease: synopsis of the kidney disease: improving global outcomes 2012 clinical practice guideline. Ann Intern Med. 2013;158(11):825-30. https://doi.org/10.7326/0003-4819-158-11-2013 06040-00007.

14. Hamm CW, Bassand JP, Agewall S, Bax J, Boersma E, Bueno H, et al. ESC guidelines for the management of acute coronary syndromes in patients presenting without persistent ST-segment elevation: the task force for the management of acute coronary syndromes (ACS) in patients presenting without persistent ST-segment elevation of the European Society of Cardiology (ESC). Eur Heart J. 2011;32(23):2999-3054. https://doi.org/10.1 093/eurheartj/ehr236.

15. Roffi M, Patrono C, Collet JP, Mueller C, Valgimigli M, Andreotti F, et al. 2015 ESC guidelines for the management of acute coronary syndromes in patients presenting without persistent ST-segment elevation: task force for the Management of Acute Coronary Syndromes in patients presenting without persistent ST-segment elevation of the European Society of Cardiology (ESC). Eur Heart J. 2016;37(3):267-315. https://doi.org/10.1093/ eurheartj/ehv320.

16. Inker LA, Astor BC, Fox CH, Isakova T, Lash JP, Peralta CA, et al. KDOQI US commentary on the $2012 \mathrm{KDIGO}$ clinical practice guideline for the evaluation and management of CKD. Am J Kidney Dis. 2014;63(5):713-35. https://doi.org/10.1053/j.ajkd.2014.01.416.

17. Lin J, Knight EL, Hogan ML, Singh AK. A comparison of prediction equations for estimating glomerular filtration rate in adults without kidney disease. J Am Soc Nephrol. 2003;14(10):2573-80. https://doi.org/10.1097/01.ASN 0000088721.98173.4B.

18. Matsushita K, Mahmoodi BK, Woodward M, Emberson JR, Jafar TH, Jee SH, et al. Comparison of risk prediction using the CKD-EPI equation and the MDRD study equation for estimated glomerular filtration rate. JAMA. 2012; 307(18):1941-51. https://doi.org/10.1001/jama.2012.3954.

19. Carter JL, Stevens PE, Irving JE, Lamb EJ. Estimating glomerular filtration rate: comparison of the CKD-EPI and MDRD equations in a large UK cohort with particular emphasis on the effect of age. QJM. 2011;104(10):839-47. https:// doi.org/10.1093/qjmed/hcr077.

20. Willems JM, Vlasveld T, den Elzen WP, Westendorp RG, Rabelink TJ, de Craen AJ, et al. Performance of Cockcroft-Gault, MDRD, and CKD-EPI in estimating prevalence of renal function and predicting survival in the oldest old. BMC Geriatr. 2013;13(1):113. https://doi.org/10.1186/1471-2318-13-113.
21. Jo JY, Ryu SA, Kim Jl, Lee EH, Choi IC. Comparison of five glomerular filtration rate estimating equations as predictors of acute kidney injury after cardiovascular surgery. Sci Rep. 2019;9(1):11072. https://doi.org/10.1038/s41 598-019-47559-w.

22. Fu S, Liu Y, Zhu B, Xiao T, Yi S, Bai Y, et al. Prognostic abilities of different calculation formulas for the glomerular filtration rate in elderly Chinese patients with coronary artery disease. Clin Interv Aging. 2013;8:229-37. https://doi.org/10.2147/CIA.S40438.

23. Rigalleau V, Beauvieux MC, Gonzalez C, Raffaitin C, Lasseur C, Combe C, et al. Estimation of renal function in patients with diabetes. Diabetes Metab. 2011;37(5):359-66. https://doi.org/10.1016/j.diabet.2011.05.002.

24. Saleem M, Florkowski CM, George PM. Comparison of the Mayo Clinic quadratic equation with the modification of diet in renal disease equation and radionuclide glomerular filtration rate in a clinical setting. Nephrology (Carlton). 2008;13(8):684-8. https://doi.org/10.1111/j.1440-1797.2008.01045.x.

25. Mandelli S, Riva E, Tettamanti M, Detoma P, Giacomin A, Lucca U. Mortality prediction in the oldest old with five different equations to estimate glomerular filtration rate: the health and Anemia populationbased study. PLoS One. 2015;10(8):e0136039. https://doi.org/10.1371/ journal.pone.0136039.

26. Carnevale V, Pastore L, Camaioni M, Mellozzi M, Sabatini M, Arietti E, et al. Estimate of renal function in oldest old inpatients by MDRD study equation, Mayo Clinic equation and creatinine clearance. J Nephrol. 2010;23(3):306-13.

\section{Publisher's Note}

Springer Nature remains neutral with regard to jurisdictional claims in published maps and institutional affiliations.
Ready to submit your research? Choose BMC and benefit from:

- fast, convenient online submission

- thorough peer review by experienced researchers in your field

- rapid publication on acceptance

- support for research data, including large and complex data types

- gold Open Access which fosters wider collaboration and increased citations

- maximum visibility for your research: over $100 \mathrm{M}$ website views per year

At BMC, research is always in progress.

Learn more biomedcentral.com/submissions 